\title{
Avaliação das características estruturais do capim-braquiária em pastagens adubadas com nitrogênio nas quatro estações do ano ${ }^{1}$
}

\author{
Jailson Lara Fagundes ${ }^{2}$, Dilermando Miranda da Fonseca ${ }^{3}$, Rodrigo Vieira de Morais ${ }^{4}$, \\ Claudio Mistura ${ }^{5}$, Claudio Manoel Teixeira Vitor ${ }^{4}$, José Alberto Gomide ${ }^{3}$, Domicio do Nasci- \\ mento Junior ${ }^{3}$, Manoel Eduardo Rozalino Santos ${ }^{6}$, Daniel Moreira Lambertucci ${ }^{6}$
}

\footnotetext{
${ }^{1}$ Parte da tese de Doutorado do primeiro autor.

2 Pólo Regional da Alta Paulista - APTA/SAA/SP, Bairro da estrada 14, km 11,c.x. 191, CEP: 17800-000, Adamantina, SP.

${ }^{3}$ Departamento de Zootecnia - Universidade Federal de Viçosa, CEP: 36570-000, Viçosa-MG.

${ }^{4}$ Pós-graduação em Zootecnia - Universidade Federal de Viçosa, CEP: 36571-000, Viçosa - MG.

${ }^{5}$ Departamento de Zootecnia - Universidade do Estado da Bahia, CEP: 48100-000, Juazeiro, BA.

${ }^{6}$ Zootecnista.
}

RESUMO - Este experimento foi realizado com o objetivo de avaliar o efeito da adubação nitrogenada sobre a demografia de perfilhos e a biomassa forrageira em pastagens de Brachiaria decumbens cv. Basilisk submetidas à mesma intensidade de pastejo. Os tratamentos consistiram da aplicação de quatro doses de nitrogênio (75, 150, 225 e 300 kg/ha.ano) antes do período das avaliações experimentais, realizadas durante as estações verão, outono, inverno e primavera de 2002. O delineamento foi em blocos completos, casualizados com duas repetições. A demografia populacional de perfilhos e a biomassa forrageira de B. decumbens variaram com as estações do ano e com as doses de nitrogênio. A densidade populacional de perfilhos vegetativos e vivos aumentou linearmente, enquanto a de perfilhos mortos decresceu linearmente com as doses de N. A biomassa forrageira também aumentou linearmente, ao passo que a densidade populacional de perfilhos reprodutivos não foi influenciada pela adubação nitrogenada. A densidade populacional de perfilhos vivos, vegetativos e reprodutivos e a biomassa de folhas, de colmo e de material verde de Brachiaria decumbens variaram entre as estações do ano, apresentando valores menores no inverno.

Palavras-chave: adubação nitrogenada, biomassa forrageira, Brachiaria decumbens, forragem, pastejo, perfilho

\section{Evaluation of structural characteristics of the signalgrass in a nitrogen fertilized pasture over the seasons of the year}

\begin{abstract}
This trial was carried out from November 2001 to November 2002, aiming at the evaluation of the effects of nitrogen fertilization upon the tiller demography and forage biomass in Brachiaria decumbens cv. Basilisk pastures fertilized with nitrogen and subjected to the same grazing height. The treatments consisted of four nitrogen rates (75, 150, 225 and $300 \mathrm{~kg} / \mathrm{ha}$.yr.) applied before the beginning of the experimental evaluations, which were performed during the Summer, Fall, Winter and Spring, 2002. A completely randomized block experimental design was used with two replications. Seasons and nitrogen rates affected grass tiller population density and forage biomass. The population density of alive and vegetative tillers increased linearly, while that of the dead tillers decreased linearly with the $\mathrm{N}$ rates. Forage biomass increased linearly with nitrogen fertilization, whereas the population density of reproductive tillers were not affected by nitrogen fertilization. The alive tiller population density, vegetative and reproductive, leaf biomass, stem and green matter of the Brachiaria decumbens varied among the seasons, with lower values in Winter.
\end{abstract}

Key Words: nitrogen fertilization, forage biomass, Brachiaria decumbens, forage, tiller, grazing

\section{Introdução}

Nos ecossistemas de pastagens, a exploração das plantas forrageiras e de animais em pastejo é conflitante, uma vez que a comunidade de plantas necessita manter sua área foliar com elevada eficiência fotossintética e os animais precisam ser alimentados com forragem de boa qualidade. É importante compreender a inter-relação entre os componentes do sistema de pastagens, incluindo, necessariamente, as características estruturais do dossel forrageiro, condicionadoras e determinantes de respostas de plantas e de animais, de modo que a estrutura da pastagem seja o elo desses componentes. Dessa forma, torna-se relevante o conhecimento da dinâmica de produção das gramíneas forrageiras, por meio de avaliações das características estruturais, por possibilitarem o estudo do crescimento vegetal (Lemaire \& Chapman, 1996).

A estrutura do dossel forrageiro é definida como a distribuição e o arranjo das partes da planta, ou a quantidade e organização de seus componentes, dentro de sua comunidade, sobre 
o solo (Laca \& Lemaire, 2000). Portanto, a estrutura da pastagem - determinada por sua morfologia e arquitetura, pela distribuição espacial das folhas, pelas relações folha:colmo e material morto:vivo, pela densidade de folhas verdes, pela densidade populacional de perfilhos e pela altura-interfere na produção de forragem e no consumo de massa seca pelos animais.

O potencial de produção de uma planta forrageira é determinado geneticamente. Entretanto, para que este potencial seja alcançado, as condições adequadas do meio e o manejo devem ser observados. Entre estas condições, nas regiões tropicais, a baixa disponibilidade de nutrientes é, seguramente, um dos fatores que mais interferem na produtividade e na qualidade da forrageira. Assim, o fornecimento de nutrientes em quantidades e proporções adequadas, particularmente o nitrogênio, assume importância fundamental no processo produtivo de pastagens, pois o nitrogênio do solo, proveniente da mineralização da matéria orgânica, não é suficiente para atender à demanda de gramíneas com alto potencial produtivo.

Os efeitos da adubação nitrogenada e das épocas de avaliação sobre a população de perfilhos podem, no entanto, constituir os principais fatores determinantes da produção de biomassa, juntamente com o rendimento por perfilho (Nelson et al., 1977). Ademais, o perfilhamento da planta forrageira é uma resposta das plantas à fertilidade do solo, associada à época, à freqüência e ao intervalo entre cortes (Corsi \& Nascimento Jr., 1994).

Portanto, mesmo que os processos, mecanismos e princípios que determinam a produção forrageira sejam idênticos, a expressão das respostas dessas plantas assume valores distintos para cada espécie, visto que a plasticidade fenotípica, responsável pela amplitude das compensações entre esses processos e mecanismos, é singular e específica (Hodgson \& Da Silva, 2002), justificando, ainda mais, a necessidade do conhecimento mais detalhado sobre a planta forrageira (Da Silva \& Pedreira, 1997), uma vez que mudanças morfológicas na pastagem ocorrem ao longo do tempo (Euclides \& Euclides Filho, 1997).

Em decorrência da carência de informações sobre o comportamento de características estruturais das gramíneas tropicais sob pastejo e adubação com nitrogênio em condições climáticas distintas, realizou-se este trabalho com o objetivo de estudar o efeito da adubação nitrogenada sobre a demografia de perfilhos e a biomassa de forragem em pastagens de Brachiaria decumbens cv. Basilisk nas quatro estações do ano.

\section{Material e Métodos}

O experimento foi conduzido em uma pastagem de Brachiaria decumbens cv. Basilisk (Stapf.), estabelecida em 1997 e utilizada, até novembro de 2001, em outras pesquisas nas quais a adubação não era o fator em estudo. A área experimental pertence ao Departamento de Zootecnia da Universidade Federal de Viçosa (UFV), localizada em Viçosa-MG (2045' S ; 42 ${ }^{\circ} 51^{\prime} \mathrm{W}$; $\left.651 \mathrm{~m}\right)$.

O solo da área experimental foi classificado como Latossolo Vermelho-Amarelo de textura argilosa, com relevo medianamente ondulado, e apresentou as seguintes características químicas na camada 0-20 cm: $\mathrm{pH}$ em $\mathrm{H}_{2} \mathrm{O}: 5,2 ; \mathrm{P}: 5,18$ (Mehlich1)eK: $148,75 \mathrm{mg} / \mathrm{dm}^{3} ; \mathrm{Ca}^{+2}: 2,83 ; \mathrm{Mg}^{+2}: 0,82 \mathrm{eAl}^{+3}$ : $0,13 \mathrm{cmol}_{\mathrm{C}} / \mathrm{dm}^{3}(\mathrm{KCl} 1 \mathrm{~mol} / \mathrm{L})$ e matéria orgânica 42,4 g/kg (Walkley \& Black). Considerando-se os resultados da análise do solo, realizou-se adubação com $\mathrm{P}_{2} \mathrm{O}_{5}(100 \mathrm{~kg} / \mathrm{ha})$, na forma de superfosfato simples, e com $\mathrm{K}_{2} \mathrm{O}$ (150 kg/ha), na forma de cloreto de potássio, aplicados em cobertura em toda a área experimental.

Em setembro de 2001, a pastagem foi submetida a pastejo pesado, para redução da biomassa, e a roçada, realizada a $10 \mathrm{~cm}$ do nível do solo, após o pastejo, para o rebaixamento da altura das plantas em todos os piquetes.

Os tratamentos consistiram de quatro doses de nitrogênio (75, 150, 225 e 300 kg/ha.ano), aplicadas antes do início das avaliações. $\mathrm{O}$ adubo nitrogenado (uréia) correspondente às doses foi distribuído em três aplicações (14-11-01, 26-01-02 e 21-03-02), exceto a dose de 75 kg/ha.ano de $\mathrm{N}$, que foi dividida em apenas duas aplicações (14-11-01 e 26-01-02). As unidades experimentais consistiram de oito piquetes com áreas variando de 0,2 a 0,4 ha, inversamente à dose de $\mathrm{N}$ aplicada, para permitir taxa de lotação mais uniforme em todos os piquetes. Utilizou-se o delineamento em blocos completos casualizados, com duas repetições.

No período de 09 de novembro de 2001 a abril de 2002, a pastagem foi manejada sob lotação contínua com taxa de lotação variável, utilizando-se novilhos mestiços nelore com peso inicial de 180 a $210 \mathrm{~kg}$. Em cada piquete, manteve-se um mínimo de dois animais durante o período de avaliação. A altura média da pastagem foi mantida em torno de $20 \mathrm{~cm}$, por meio da adição ou retirada de animais reguladores. No período de maio a novembro de 2002, foram realizados dois pastejos lenientes: um de 29/06 a 06/07 e outro de 02 a 10/09, para a manutenção da altura média da pastagem.

A temperatura média diária mensal durante o período de avaliação variou de 18,7 a $24^{\circ} \mathrm{C}$. A precipitação pluvial total foi de $466,7 \mathrm{~mm}$, a evaporação total de $779 \mathrm{~mm}$ e a umidade relativa variou entre 68,1 e $82,8 \%$ (Tabela 1 ). 
Tabela 1 - Médias mensais das temperatura máxima, mínima e média diária, precipitação pluvial total mensal e evaporação total mensal (média mensal) durante o período de março a novembro de 2002

Table 1 - Monthly averages of the maximum, minimum and daily average temperatures, monthly total rain and monthly total evaporation (monthly average) from March to November 2002

\begin{tabular}{|c|c|c|c|c|c|}
\hline \multirow{3}{*}{$\begin{array}{l}\text { Mês } \\
\text { Month }\end{array}$} & \multicolumn{3}{|c|}{$\begin{array}{c}\text { Temperatura média do ar }\left({ }^{\circ} \mathrm{C}\right) \\
\text { Average air temperature }\left({ }^{\circ} \mathrm{C}\right)\end{array}$} & $\begin{array}{c}\text { Precipitação } \\
\text { Rainfall }\end{array}$ & \multirow[t]{3}{*}{$\begin{array}{l}\text { Evaporação } \\
\text { Evaporation }\end{array}$} \\
\hline & Máxima & Mínima & Média & \multirow[t]{2}{*}{$(\mathrm{mm})$} & \\
\hline & Maximum & Minimum & Average & & \\
\hline Março (March) & 29,6 & 18,3 & 24,0 & 98,5 & 78,8 \\
\hline Abril (April) & 30,8 & 17,1 & 24,0 & 1,8 & 85,0 \\
\hline Maio (May) & 26,4 & 15,2 & 20,8 & 37,6 & 64,9 \\
\hline Junho (June) & 26,2 & 12,2 & 19,2 & 2,2 & 68,4 \\
\hline Julho (July) & 24,9 & 12,5 & 18,7 & 1,6 & 66,8 \\
\hline Agosto (August) & 27,7 & 13,0 & 20,4 & 0,1 & 104,6 \\
\hline Setembro (September) & 25,0 & 14,6 & 19,8 & 77,2 & 85,2 \\
\hline Outubro (October) & 29,8 & 16,2 & 23,0 & 29,5 & 145,1 \\
\hline Novembro (November) & 27,8 & 18,1 & 23,0 & 218,2 & 80,2 \\
\hline
\end{tabular}

Fonte: Estação metereológica do Departamento de Engenharia Agrícola da UFV.

Source: UFV meteorological station, Agricultural Engineering Department.

As avaliações foram realizadas entre março e novembro de 2002, utilizando-se, para efeito das análises estatísticas, os valores médios de março (verão), abril, maio, junho (outono), julho, agosto, setembro (inverno), outubro e novembro (primavera).

Alcançada e mantida a altura da pastagem de $20 \mathrm{~cm}$ nos piquetes, iniciaram-se as avaliações da biomassa forrageira, da demografia populacional de perfilhos e do acúmulo de forragem.

Para avaliação da biomassa forrageira, foram colhidas três amostras de forragem em $0,16 \mathrm{~m}^{2}$ (quadrado de $40 \times 40 \mathrm{~cm}$ ) por unidade experimental, efetuando-se cortes rente ao solo em intervalos de 30 dias. A unidade amostral $\left(0,16 \mathrm{~m}^{2}\right)$ foi constituída, sempre, de plantas da área da unidade experimental com altura média de $20 \mathrm{~cm}$.

As amostras de forragem foram subamostradas e fracionadas em lâminas foliares verdes, colmos verdes (colmo + bainha foliar) e material morto (perfilhos e folhas mortos). Após a separação, todos os componentes foram secos em estufa a $65^{\circ} \mathrm{C}$ até peso constante. Após secagem, as amostras foram pesadas em balança analítica e, por meio das relações massa seca $\mathrm{x}$ massa verde da subamostra, calculou-se a MS de cada componente da forragem colhida na área de amostragem $\left(0,16 \mathrm{~m}^{2}\right)$.

A partir da participação dos componentes lâmina foliar, colmo e material morto na massa seca total de cada amostra, estimou-se a biomassa de cada um dos componentes no dossel forrageiro.

A avaliação da densidade volumétrica de forragem (kg/ha.cm) foi obtida pela divisão da biomassa de material verde ( $\mathrm{kg} / \mathrm{ha}$ ) pela altura em que a pastagem foi manejada $(20 \mathrm{~cm})$.

Para avaliação da densidade populacional de perfilhos, foram colhidas três amostras de plantas em cada piquete, mantido a $20 \mathrm{~cm}$ de altura, em uma área de $0,0625 \mathrm{~m}^{2}$. Cada avaliação foi realizada no período máximo de dois dias, a intervalos de aproximadamente quatro semanas. Após a colheita, as amostras foram levadas ao laboratório para separação e contagem do número total de perfilhos basais reprodutivos, vegetativos e mortos.

A análise de variância dos dados foi realizada considerando-se o delineamento em blocos completos casualizados com medidas repetidas no tempo, utilizando-se o procedimento PROC MIXED do programa SAS (SAS, 2002). Os efeitos das estações do ano sobre a demografia populacional de perfilhos, a biomassa forrageira e o acúmulo de forragem foram avaliados por meio do teste Tukey, a 5\%, e o efeito das doses de nitrogênio, pelo ajuste de regressões.

\section{Resultados e Discussão}

O número de perfilhos vegetativos, reprodutivos, vivos e mortos do capim-braquiária sob pastejo variou conforme a estação do ano (Tabela 2). A densidade populacional de perfilhos vivos e vegetativos atingiu valores mínimos no inverno, provavelmente em razão das condições desfavoráveis de fatores de crescimento (água, luz e temperatura, durante aqueles meses do ano (Tabela 1). De fato, os processos de formação, desenvolvimento, crescimento e senescência de perfilhos são influenciados por condições climáticas, como temperatura e disponibilidade de água e de nutrientes (Mazzanti et al., 1994; Carvalho et al., 2000).

Na primavera e no verão, no entanto, registrou-se a maior densidade populacional de perfilhos vivos, como também foi verificado por Carvalho et al. (2000), em Cynodon spp., e por Uebele (2002), em Panicum maximum cv. Mombaça. Entretanto, em Panicum maximum cv. Tanzânia e Mombaça, 
Tabela 2 - Densidade populacional de perfilhos em pastagem de Brachiaria decumbens sob pastejo, adubada com nitrogênio e mantida a $20 \mathrm{~cm}$ de altura durante as quatro estações do ano de 2002

Table 2 - Tiller population density in Brachiaria decumbens pasture under grazing fertilized with nitrogen and kept at $20 \mathrm{~cm}$ height, over the four yearly seasons of 2002

\begin{tabular}{|c|c|c|c|c|}
\hline $\begin{array}{l}\text { Característica } \\
\text { Characteristic }\end{array}$ & $\begin{array}{l}\text { Verão } \\
\text { Summer }\end{array}$ & $\begin{array}{c}\text { Outono } \\
\text { Fall }\end{array}$ & $\begin{array}{l}\text { Inverno } \\
\text { Winter }\end{array}$ & $\begin{array}{c}\text { Primavera } \\
\text { Spring }\end{array}$ \\
\hline & \multicolumn{4}{|c|}{$\begin{array}{c}\text { Perfilhos } / \mathrm{m}^{2} \\
\text { Tillers } / \mathrm{m}^{2}\end{array}$} \\
\hline Perfilhos vegetativos (Vegetative tillers) & $1755 a b$ & 1713ab & $1573 b$ & $1904 a$ \\
\hline Perfilhos mortos (Dead tillers) & 233b & 749a & $916 a$ & $969 a$ \\
\hline Perfilhos vivos (Alive tillers) & $1864 a$ & 1788ab & $1573 b$ & 1916a \\
\hline Perfilhos reprodutivos (Reproductive tillers) & $109 a$ & $74 \mathrm{a}$ & ob & $12 \mathrm{~b}$ \\
\hline
\end{tabular}

Médias seguidas de letras iguais, na linha, não diferem $(P>0,05)$ pelo teste $F$.

Averages followed by the same letter, in a row, do not differ $(P>0.05)$ by F test.

a densidade populacional de perfilhos foi maior no final da primavera (novembro/dezembro) e manteve-se relativamente constante nas demais estações do ano (Santos, 1997).

A densidade populacional de perfilhos mortos atingiu valores mínimos no verão (Tabela 2), provavelmente em decorrência da metodologia utilizada na avaliação do perfilhamento, pois foram realizados cortes e contagem de perfilhos em épocas distintas, de modo que os perfilhos mortos em uma estação foram computados na estação seguinte. Contudo, estes resultados corroboram aqueles descritos por Korte et al. (1982), segundo os quais o déficit hídrico provocou elevação da taxa de mortalidade de perfilhos. Korte \& Chu (1983) também relataram reduções e incrementos na taxa de natalidade de perfilhos, durante e logo após um período de seca, respectivamente.

No entanto, Uebele (2002) e Carvalho et al. (2000), em estudo sobre a dinâmica de perfilhos em Panicum e Cynodon, verificaram maiores taxas de mortalidade e natalidade de perfilhos nos períodos de primavera e verão, sugerindo a ocorrência de um padrão intenso de renovação de perfilhos.

Os mais altos valores na densidade populacional de perfilhos reprodutivos foram verificados no verão e no outono (Tabela 2) e provavelmente decorreram da baixa sensibilidade da Brachiaria decumbens ao fotoperíodo, conforme relatado por Andrade (1994). As informações na literatura também são consistentes quanto à redução na natalidade de perfilhos durante a fase de desenvolvimento reprodutivo das plantas (Hernandez Garay et al., 1997).

Ressalta-se que as plantas utilizam alguns mecanismos para limitar a superfície transpirante e retardar o agravamento da deficiência hídrica, que provoca grandes alterações em seu padrão de crescimento. Entre estes mecanismos, destacam-se a inibição do perfilhamento e da ramificação, a antecipação da morte dos perfilhos estabelecidos, a redução da área foliar, pela aceleração da senescência das folhas mais velhas, e o maior crescimento do sistema radicular (Morales et al.,
1997). Nabinger \& Pontes (2001) descreveram que, para manter o desenvolvimento do perfilho em condições limitantes do crescimento, parece lógico que a economia de assimilados comece pelo comprometimento do perfilhamento, passando pela redução no tamanho e no período de vida da folha. Este comportamento explicaria a elevação na densidade de perfilhos mortos no capim-braquiária neste experimento, em resposta à mudança de estações do ano.

Outra possível explicação para a alteração na densidade populacional de perfilhos seria o fato de comunidades de plantas sob pastejo adaptarem-se às condições e intensidades de desfolhação (Hernandez Garay et al., 1997; Matthew et al., 1999). Entretanto, como a intensidade de desfolhação, neste experimento, foi mantida constante, as mudanças na densidade populacional de perfilhos devem ser atribuídas às condições nutricionais das plantas e às mudanças climáticas.

Houve efeito das doses de $\mathrm{N}$ na densidade de perfilhos vegetativos e vivos (Figura 1 ) da B. decumbens sob pastejo, observando-se resposta linear positiva $(\mathrm{P}<0,05)$. Esta influência do nitrogênio na densidade populacional de perfilhos tem sido observada em cultivares de Panicum maximum (Alcântara et al., 1985) e Lolium perenne (Mckenzie, 1996).

A magnitude de resposta da demografia populacional de perfilhos vegetativos e vivos às doses de $\mathrm{N}$ foi pequena, de 3,14 e 3,18 perfilhos/kg de N, respectivamente (Figura 1), o que pode ser atribuído ao efeito residual das doses de nitrogênio aplicadas na pastagem com a forrageira mantida sob mesma altura, o que difere do observado por Pinto et al.(1994), que realizaram as avaliações logo após a aplicação do nutriente, em casa de vegetação, na fase de estabelecimento e rebrotação das forrageiras.

Conforme demonstrado por Mazzanti \& Lemaire (1994), o aumento na densidade de perfilhos é o processo pelo qual a produção de forragem é incrementada com adubação de $\mathrm{N}$, em pastagens sob lotação contínua, pois, nessas condições, a taxa de alongamento foliar em nível de perfilho não responde muito à nutrição de N. Portanto, a manipulação da 
dinâmica do perfilhamento pode ser importante estratégia para o manejo da pastagem, principalmente porque a densidade populacional de perfilhos é determinante da perenidade da pastagem (Lemaire \& Chapman, 1996). Neste contexto, o conhecimento da dinâmica populacional de perfilhos reveste-se de importância, pois auxilia na definição de estratégias de manejo de pastagens, contribuindo para aumentos significativos em sua produtividade em situações específicas (Matthew et al., 1999).

As maiores densidades de perfilhos vivos e vegetativos foram observadas durante a primavera, seguidas pelas de verão e outono e, finalmente, pelas de inverno. Esses resultados, em associação à maior densidade de perfilhos mortos na primavera e no inverno (Tabela 2), desconsiderando-se possível efeito do erro acumulativo na contagem dos perfilhos mortos, mantidos no relvado ao longo da estação, indicam a ocorrência de grande renovação de perfilhos durante os meses de primavera. Assim, práticas de manejo que assegurem altas taxas de natalidade de perfilhos durante a primavera tornam-se essenciais para a manutenção e/ou incremento da densidade populacional de perfilhos durante as estações de verão, outono e inverno.

A biomassa do capim-braquiária apresentou variação com a estação do ano (Tabela 3). Essa variação estacional da massa seca de lâminas verdes (MSLF), de colmo (MSC) e de material verde seco (folha + colmo) (MVS) reflete a atuação dos fatores climáticos na morfologia das plantas, alterando o número de folhas vivas por perfilho, o alongamento foliar, o comprimento final da folha, a relação folha:colmo e a densidade populacional de perfilhos.

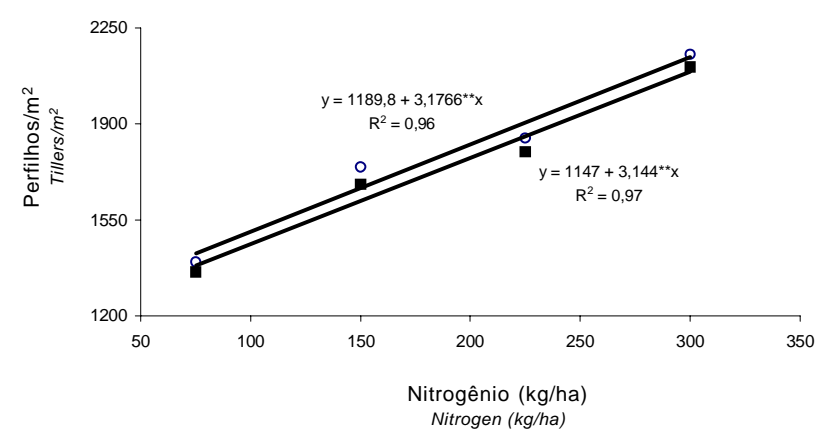

Figura 1 - Densidade populacional de perfilhos vegetativos (O) e vivos ( $\boldsymbol{\square}$ ) em pastagens de Brachiaria decumbens sob pastejo adubada com nitrogênio. Significativo a $\left.1 \%{ }^{* *}\right)$.

Figure 1 - Population density of tiller vegetative $(\mathrm{O})$ and alive $(\boldsymbol{\square})$ in Brachiaria decumbens under grazing, as function of nitrogen rate. Significant at $1 \%$ level $\left({ }^{* *}\right)$.
A biomassa de MSLF durante os períodos de verão, outono, inverno e primavera correspondeu a 35,3; 29,6; 30,1 e 37,9\% da biomassa de MVS. A biomassa de MVS é aparentemente satisfatória para garantir a estabilidade do relvado e a produção animal, visto que seus valores são superiores à taxa de 1.200 a $1.600 \mathrm{~kg} / \mathrm{ha}$ de MSV preconizada por Mott (1984) para garantir consumo satisfatório de forragem. Os menores valores de biomassa de MSLF, MSC e MVS verificados no inverno (Tabela 3) decorrem das condições climáticas desfavoráveis, como baixas temperaturas e precipitações pluviais (Tabela 1).

A contribuição diferenciada dos componentes da pastagem ao longo das estações explica os menores valores de MVS encontrados no período de inverno, uma vez que a seqüência natural da estacionalidade na produção de massa seca de folhas e de colmo resulta da influência das estações do ano no ciclo anual de crescimento da gramínea. Essa seqüência, no entanto, não ocorreu com a produção de massa verde seca durante a estação de inverno, que apresentou menores valores e não se diferenciou nas demais estações do ano.

$\mathrm{Na}$ avaliação do efeito das doses de $\mathrm{N}$ na biomassa de MSLF, MSC e MVS, observou-se ajuste linear aos resultados (Figura 2). Apesar de significativa, a magnitude do efeito da adubação nitrogenada foi pequena e, conforme mencionado anteriormente, pode ser atribuída ao efeito residual da adubação nitrogenada. É importante ressaltar ainda que a influência da adubação nitrogenada na demografia populacional de perfilhos pode ser a principal causa do incremento na biomassa forrageira, juntamente com o rendimento por perfilho (Nelson et al., 1977).

Euclides \& Euclides Filho (1997) também apontaram que, ao longo do tempo, ocorreram mudanças morfológicas na pastagem. Durante a estação de crescimento, observaram-se acréscimo na proporção de colmo em relação à de folhas e acúmulo de material morto, como consequência da senescência natural da planta forrageira, ocasionada pelo déficit hídrico da estação anterior.

Portanto, é fundamental o conhecimento da variação na biomassa de massa verde seca de folhas e de material verde das pastagens submetidas a diferentes condições de manejo e de ambiente, nas diversas épocas do ano, para que sejam alcançados desempenho satisfatório dos animais e máxima produção por unidade de área (Carvalho \& Damasceno, 1996).

A densidade volumétrica de forragem (kg/ha.cm) apresentou variação com as estações do ano (Tabela 3). Menores valores de densidade volumétrica ocorreram no inverno, em relação às demais estações, como resultado da maior presença de material verde ao longo do perfil do dossel. No inverno, além da menor participação de material 
Tabela 3 - Massa seca (kg/ha) e densidade volumétrica de forragem (kg/ha.cm) em pastagem de Brachiaria decumbens sob pastejo, adubada com nitrogênio e mantida a $20 \mathrm{~cm}$ de altura durante as quatro estações do ano

Table 3 - Dry matter biomass $(\mathrm{kg} / \mathrm{ha}$ ) and bulk density $(\mathrm{kg} / \mathrm{ha} . \mathrm{cm})$ in Brachiaria decumbens pasture under grazing fertilized with nitrogen and kept at $20 \mathrm{~cm}$ height, over the four yearly seasons

\begin{tabular}{|c|c|c|c|c|}
\hline $\begin{array}{l}\text { Característica } \\
\text { Characteristic }\end{array}$ & $\begin{array}{l}\text { Verão } \\
\text { Summer }\end{array}$ & $\begin{array}{l}\text { Outono } \\
\text { Fall }\end{array}$ & $\begin{array}{l}\text { Inverno } \\
\text { Winter }\end{array}$ & $\begin{array}{l}\text { Primavera } \\
\text { Spring }\end{array}$ \\
\hline $\begin{array}{l}\text { Biomassa de laminas verdes }(\mathrm{kg} / \mathrm{ha}) \\
\text { Blade green biomass }(\mathrm{kg} / \mathrm{ha})\end{array}$ & $1651 \mathrm{ab}$ & $1432 b$ & $1095 c$ & $1850 a$ \\
\hline $\begin{array}{l}\text { Biomassa de colmo }(\mathrm{kg} / \mathrm{ha}) \\
\text { Stem biomass }(\mathrm{kg} / \mathrm{ha})\end{array}$ & $3028 a b$ & $3348 a$ & $2545 b$ & 3033ab \\
\hline $\begin{array}{l}\text { Biomassa de material verde }(\mathrm{kg} / \mathrm{ha}) \\
\text { Green material biomass }(\mathrm{kg} / \mathrm{ha})\end{array}$ & $4679 a$ & $4780 a$ & $3640 \mathrm{~b}$ & 4883a \\
\hline $\begin{array}{l}\text { Densidade de forragem (kg/ha.cm) } \\
\text { Bulk density ( } \mathrm{kg} / \mathrm{ha} . \mathrm{cm})\end{array}$ & $234 a$ & $242 \mathrm{a}$ & $182 b$ & $244 a$ \\
\hline
\end{tabular}

Médias seguidas de letras iguais, na linha, não diferem $(P>0,05)$ pelo teste $F$.

Averages followed by the same letter, in a row, do not differ $(P>0.05)$ by F test,

verde, a menor densidade volumétrica de forragem pode ainda ser atribuída ao baixo número de folhas vivas por perfilho, ao menor tamanho das folhas e à baixa densidade populacional de perfilhos vivos.

Observou-se resposta linear positiva do nitrogênio na densidade volumétrica de biomassa de Brachiaria decumbens às doses de $\mathrm{N}$ (Figura 3 ), explicada pela manutenção de elevada população de perfilhos vivos na pastagem.

A densidade volumétrica média de $B$. decumbens no experimento foi de $226 \mathrm{~kg} / \mathrm{ha}$.cm de MS, com amplitude de 98,7 a 284,4 kg/ha.cm de MS quando as doses de N variaram de 75 a $300 \mathrm{~kg} / \mathrm{ha}$. Esses valores são inferiores àqueles reportados na literatura para outras espécies forrageiras, como Cynodon spp., de -403 kg/ha.cm de MS (Fagundes et al., 1999), coastcross (Cynodon spp.), de - 290 kg/ha.cm de MS (Carnevalli et al., 2001), porém, superiores aos reportados para capim-elefante cv. Guaçu (Pennisetum purpureum), de $69 \mathrm{~kg} / \mathrm{ha} . \mathrm{cm}$ de MS, e para o capimtanzânia, de -81 kg/ha.cm de MS (Pedreira et al., 2000).

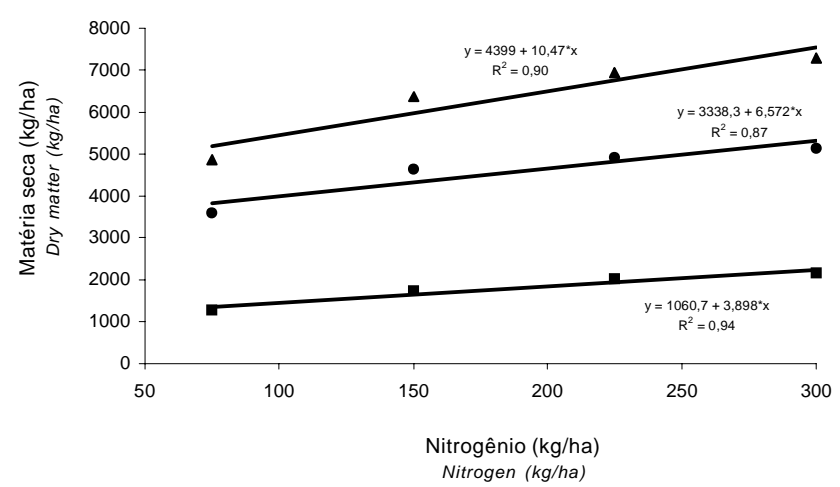

Figura 2 - Biomassa de lâminas verdes (ם), colmos (O) e material verde $(\boldsymbol{\Delta})$ de Brachiaria decumbens, de acordo com as doses de nitrogênio. Significativo a $5 \%\left(^{*}\right)$.

Figure 2 - Green blade biomass $(\boldsymbol{\square})$, stems ( $O$ ) and green matter $(\boldsymbol{\Delta})$ in Brachiaria decumbens, as a function of the nitrogen rates. Significant at $5 \%$ level $(*)$.
Segundo Stobbs (1973), em pastagens de clima temperado, a densidade volumétrica de forragem é o principal componente da estrutura a determinar a taxa de consumo em pastagens tropicais. Neste sentido, correlações positivas entre as densidades de folhas e a relação folha:colmo com o consumo foram observadas em vários experimentos em pastagens tropicais (Stobbs, 1973; Hendricksen \& Minson, 1980). Os resultados de densidades volumétricas de forragem observados neste trabalho corroboram os valores estabelecidos por Stobbs (1975), de 14 a $200 \mathrm{~kg} / \mathrm{ha} . c m$ de MS para forrageiras tropicais, e os observados por Heringer \& Moojen (2002), de 5 a 208 kg/ha.cm de MS para milheto (Pennisetum americanum L.).

A adubação nitrogenada é uma estratégia que permite aumentar a densidade volumétrica de forragem e, sobretudo, a produção de folhas no perfil da pastagem, pois o $\mathrm{N}$ tem efeito significativo sobre a taxa de aparecimento e alongamento de folhas nas gramíneas (Mazzanti et al., 1994).

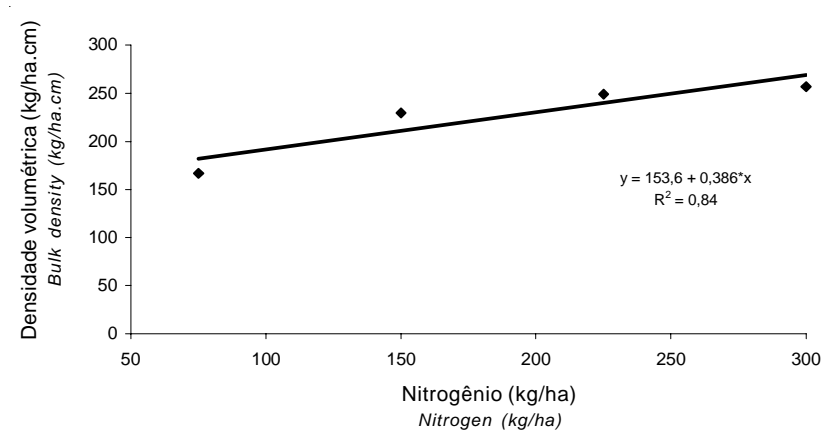

Figura 3 - Densidade volumétrica de forragem $(\mathrm{kg} / \mathrm{ha} . \mathrm{cm})$ em pastagem de Brachiaria decumbens sob pastejo adubada com nitrogênio. Significativo a 5\% (*).

Figure 3 - Bulk density (kg/ha.cm) in Brachiaria decumbens under grazing, as function of nitrogen rates. Significant at $5 \%$ level $\left(^{*}\right)$. 


\section{Conclusões}

A densidade populacional de perfilhos vivos e vegetativos, a biomassa de forragem e a densidade volumétrica de forragem aumentaram linearmente, enquanto a densidade de perfilhos mortos decresceu com a adubação nitrogenada da Brachiaria decumbens cv. Basilisk sob pastejo.

A densidade populacional de perfilhos vivos, vegetativos e reprodutivos, a densidade volumétrica de forragem e a biomassa de folhas, colmo e material verde de Brachiaria decumbens variaram entre estações do ano, apresentando menores valores no inverno.

As variações das condições climáticas com as estações do ano alteraram a demografia de perfilhos, a biomassa e a densidade volumétrica de forragem de Brachiaria decumbens cv. Basilisk sob pastejo.

\section{Literatura Citada}

ALCÂNTARA, V.B.G.; ALMEIDA, A.R.P; GHISI, O.M.A.A. Estudos fisiológicos de seis cultivares de Panicum maximum Jacq. Boletim de Indústria Animal, v.42, p.199-208, 1985.

ANDRADE, R.P. Tecnologia de produção de sementes de espécie do gênero Brachiaria. In: SIMPÓSIO SOBRE MANEJO DE PASTAGEM - Brachiaria, 11., Piracicaba, 1994. Anais... Piracicaba: Fundação de Estudos Agrários Luiz de Queiroz, 1994, p.49-72.

CARNEVALLI, R.A.; SILVA, S.C.; FAGUNDES, J.L. et al. Desempenho de ovinos e respostas de pastagens de Tifton 85 (Cynodon spp.) sob lotação contínua. Scientia Agricola, v.58, p.7-15, 2001.

CARVALHO, C.A.B.; DA SILVA, S.C.; CARNEVALLI, R.A. et al. Perfilhamento e acúmulo de forragem em pastagens de Florakirk (Cynodon spp.) sob pastejo. Boletim da Indústria Animal, v.57, n.1, p.39-51, 2000.

CARVALHO, D.D.; DAMASCENO, J.C. Aspectos fisiológicos do capim-elefante cv. Roxo-de-Botucatu. I. Taxa de aparecimento expansão e senescência de folhas. In: REUNIÃO ANUAL DA SOCIEDADE BRASILEIRA DE ZOOTECNIA, 33., 1996, Fortaleza. Anais... Fortaleza: Sociedade Brasileira de Zootecnia, 1996. p.1-3.

CORSI, M.; NASCIMENTO JR., D. Princípios de fisiologia e morfologia de plantas forrageiras aplicados no manejo das pastagens In: PEIXOTO, A.M.; MOURA, J.C.; DE FARIA, V.P. (Eds). Pastagens - Fundamentos da exploração racional, 1994. p.15-47.

DA SILVA, S.C.; PEDREIRA, C.G.S. Princípios de ecologia aplicados ao manejo de pastagem. In: FAVORETTO, V.; RODRIGUES, L. R.A; RODRIGUES, T.J.D. (Eds.) SIMPÓSIO SOBRE ECOSSISTEMA DE PASTAGENS, 3., 1997, Jaboticabal. Anais... Jaboticabal: Universidade Estadual Paulista, 1997. p.1-62.

EUCLIDES, V.P.B.; EUCLIDES FILHO, K. Avaliação de forrageiras sob pastejo. In: SIMPÓSIO SOBRE AVALIAÇÃO DE PASTAGENS COM ANIMAIS, 1997, Maringá. Anais... Maringá: Universidade Estadual de Maringá, 1997. p.85-111.

FAGUNDES, J.L.; SILVA, S.C.; PEDREIRA, C.G.S. et al. Intensidades de pastejo e a composição morfológica de pastos de Cynodon spp. Scientia Agricola, v.56, p.897-908, 1999.

HENDRICKSEN, R.; MINSON, D.J. The feed intake and grazing behaviour of cattle grazing a crop Lablab purpureus cv. Rongai. Journal of Agricultural Science, v.95, p.547-554, 1980.
HERINGER, I.; MOOJEN, E.L. Potencial produtivo, alterações da estrutura e qualidade da pastagem de milheto submetida a diferentes níveis de nitrogênio. Revista Brasileira de Zootecnia, v.31, p.875-882, 2002 (suplemento).

HERNANDEZ GARAY, A.; MATTHEW, C.; HODGSON, J. Effect of spring management on perennial ryegrass and ryegrass-white clover pastures. 2. Tiller and growing point densities and population dynamics. New Zealand Journal of Agricultural Research, v.40, p.37-50, 1997.

HODGSON, J.; DA SILVA, S.C. Options in tropical pasture management. In: REUNIÃO ANUAL DA SOCIEDADE BRASIlEIRA DE ZOOTECNIA, 39., 2002, Recife. Anais... Recife: Sociedade Brasileira de Zootecnia, 2002. p.180-202.

KORTE, C.J.; CHU, A.C.P. Some effects of drougth on perenial raygrass swards. Proceedings of the New Zealand Grassland Association, v.44, p.211-216. 1983.

KORTE, C.J.; WATKIN, B.R.; HARRIS, W. Use of residual leaf area index and light interception as criteria for spring-grazing management of a ryegrass-dominant pasture. New Zealand Journal of Agricultural Research, v.25, p.309-319, 1982.

LACA, E.A.; LEMAIRE, G. Measuring sward structure. In: MANNETJE, L.; JONES, R.M. (Eds.) Field and laboratory methods for grassland and animal production research. Wallingford: CABI Publication, 2000. p.103-121.

LEMAIRE, G.; CHAPMAN, D.F. Tissue flows in grazed plant communities. In: HODGSON, J., ILLIUS, A.W. (Eds.). The ecology and management of grazing systems. Oxon: $\mathrm{CAB}$ International, 1996. p.3-36.

MATTHEW, C.; ASSUERO, S.G.; BLACK, C.K. et al. Tiller dynamics of grazed swards. In: SIMPÓSIO INTERNACIONAL "GRASSLAND ECOPHYSIOLOGY AND GRAZING ECOLOGY”, 1999, Curitiba. Anais... Curitiba: Universidade Federal do Paraná, 1999. p.109-133.

MAZZANTI, A.; LEMAIRE, G. Effect of nitrogen fertilization on herbage production of tall fescue continuously grazed by sheep. 2 - Consumption and herbage efficiency utilization. Grass and Forage Science, v.49, p.352-359, 1994.

MAZZANTI, A.; LEMAIRE, G.; GASTAL, F. The effect nitrogen fertilization upon herbage production of tall fescue sward continuously grazed with sheep. 1 - Herbage growth dynamics. Grass and forage Science, v.49, p.111-120, 1994.

MCKENZIE, F.R. The influence of applied nitrogen on the vigour of Lolium perenne during the establishment year under subtropical conditions. Tropical Grasslands, v.30, p.345349, 1996.

MORAlES, A.; NABINGER, C.; ROSA, L.M. et al. Efeito da limitação hídrica sobre a morfogênese e repartição da biomassa de Lotus corniculatus L. cv. São Gabriel. In: REUNIÃO ANUAL DA SOCIEDADE BRASILEIRA DE ZOOTECNIA, 34., 1997, Juiz de Fora. Anais... Juiz de Fora: Sociedade Brasileira de Zootecnia, 1997. p.124-126.

MOTT, G.O. Relationship of available forage and animal performace in tropical grazing systems. In: System leading US agriculture into the future. In: FORAGE GRASSLAND CONFERENCE, 1984, Houston. Proceedings... Lexington: 1984. p.373-377.

NABINGER, C.; PONTES, L.S. Morfogênese de plantas forrageiras e estrutura do pasto. In: REUNIÃO ANUAL DA SOCIEDADE BRASILEIRA DE ZOOTECNIA, 34., 2001, Piracicaba. Anais... Piracicaba: Fundação de Estudos Agrários Luiz de Queiroz, 2001. p.755-771.

NELSON, C.J.; ASAY, K.H.; SLEPER, D.A. Mechanisms of canopy development of tall fescue genotypes. Crop Science, v.17, p.449-452, 1977.

PINTO, J.C.; GOMIDE, J.A.; MAESTRI, M. Produção de matéria seca e relação folha/caule de gramíneas forrageiras tropicais, cultivadas em vasos, com duas doses de nitrogênio. Revista Brasileira de Zootecnia, v.23, p.313-326, 1994.

PEDREIRA, C.G.S.; ROSSETO, F.A.A.; DA SILVA, S.C. et al. Forage yield and grazing efficiency on rotationally stocjed pastures of 
“Tanzania-1” guineagrass and 'Guaçu' elephantgrass. Scientia Agricola, v.62, p.433-439, 2005.

SANTOS, P.M. Estudo de algumas características agronômica de Panicum maximum (Jacq.) cvs. tanzânia e mombaça para estabelecer seu manejo. Piracicaba: Escola Superior de Agricultura Luiz de Queiroz, 1997. 62p. Dissertação (Mestrado em Ciência Animal) - Escola Superior de Agricultura Luiz de Queiroz, 1997.

STATISTICAL ANALYSES SYSTEM - SAS Disponível em: http://sasdocs.ucdavis.edu. Acesso em: 20 de abril de 2002.

STOBBS, T.H. The effect of plant structure on the intake of tropical pastures. I. Variation in bite size of grazing cattle. Australian Journal of Agricultural Research, v.24, p.809-818, 1973.

STOBBS, T.H. The effect of plant structure on the intake of tropical pasture. III. Influence of fertilizer nitrogen on the size of bite harvested by jersey cows grazing Setaria anceps cv. Kazungula swards. Australian Journal of Agricultural Research, v.26, p.997-1007, 1975.
UEBELE, M.C. Padrões demográficos de perfilhamento e produção de forragem em pastos de capim mombaça submetidos a regimes de lotação intermitente. Piracicaba: Escola Superior de Agricultura Luiz de Queiroz, 2002. 83p. Dissertação (Mestrado em Ciência Animal) - Escola Superior de Agricultura Luiz de Queiroz, 2002.

Recebido: 09/07/04 Aprovado:25/08/05 